\title{
Simbolismo sonoro do PB: o estudo dos ideofones
}

\author{
Regina Célia Fernandes Cruz \\ Universidade Federal do Pará \\ Helane de Fátima Gomes Fernandes \\ Universidade Federal do Pará
}

\section{Abstract}

[Introduction] The studies about ideophones in Brazilian Portuguese (PB) reveal that in the Portuguese system the ideophones are typically formed by bilabial sounds (CRUZ, 2000a). [aim] The main aim of this study is to verify if this is a typical feature of the PB or a resource of the sound symbolic expressivity. [methodology] In this study we observed the ideophones phenomenon in three kinds of varieties of Portuguese: (i) Afro-brazilian - ABP (CRUZ, 2000a), Brazilian dialect spoken in Amazonian by the maroon community; (ii) Amazonie Portuguese - AM (TRINDADE, 1992; CRUZ, 2000a; CASSIQUE, 1995) and (iii) standard Brazilian Portuguese - PB (OLIVEIRA, 2000; BORGES, 1991). We considered other data too: a) data collected through direct observation of different conversational situations and b) the data selected from cartoons. Particularly, we will analyse two aspects: the phonetic feature of the sounds found in the ideophones and the association of the meanings established. [results] The study of the Brazilian Portuguese ideophones show us: a) a tendency to bilabiail sounds, b) a tendency to expression links to emition of the sound and c) ideophones are not dialectal features of ABP. [conclusion] The results indicate a necessity to study more the $\mathrm{PB}$. 


\section{INTRODUÇÃO}

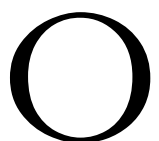

fato de o simbolismo sonoro e os ideofones serem processos que estão presentes na complexa comunicação humana é fator suficiente para que tais fenômenos mereçam ser analisados com maior profundidade.

Apesar de ser um assunto marginal na literatura, os trabalhos realizados sobre o fenômeno em outras línguas conseguem avançar bastante na definição das características gerais e típicas deste fenômeno. Entretanto, pouco se tem trabalhado sobre o referido processo no português brasileiro (doravante $\mathrm{PB}$ ). Face a essa carência, o presente trabalho se constitui em um aprofundamento da descrição do processo de formação de ideofone no PB presente em Cruz (2000a).

Das diversas definições encontradas na literatura sobre ideofones, neste trabalho destacam-se as seguintes:

[...] forms which can function as complete sentences and whose morphemic constituents are phonic features. (DIFFLOTH, 1972)

I recognize two characteristic properties: phonetic play reflecting sound symbolism, and reduplication as a structural property. (CRUZ, 2000a)

Phonetic play is the utmost intrinsic property of ideophones by which iconic relationship between the referent and the meaning can be achieved. Reduplication is the structural property that ideophones often exhibit. (LEE, 1992)

Apesar de Lee (1992) colocar em evidência o jogo fonético e a reduplicação como características importantes na formação de ideofones, a reduplicação não é considerada no presente trabalho como característica essencial na sua estrutura por dois fatores: (i) o fato de a reduplicação se fazer presente na formação das onomatopéias e (ii) o fato de o corpus utilizado apresentar dados cujo jogo fonético foi obtido sem a reduplicação. 
Conseqüentemente, neste trabalho enfocar-se-ão muito mais as características fonéticas dos ideofones. Tal aspecto fonético é reforçado na escala de Fordyce (1998, apud LEE, 1992). Fordyce (1988) estabeleceu uma escala na qual as palavras motivadas de um forte simbolismo sonoro formam um continuum entre as categorias que são tipicamente icônicas e aquelas que não o são, explicitados pelo esquema abaixo.

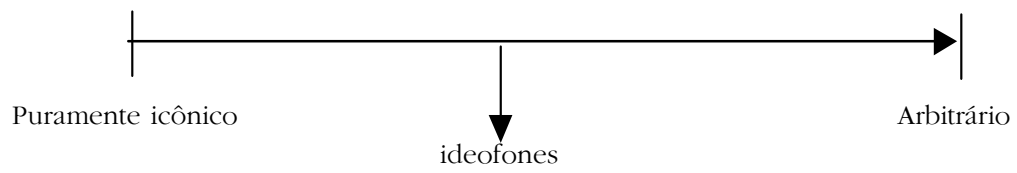

Bartens (2000) apresenta outras características atribuídas aos ideofones afirmando que são sons: a) onomatopéicos acompanhados de gestos; b) presentes na comunicação oral em situação de fala informal; c) com tendência a desaparecer quando a padronização de uma língua ganha espaço e; d) típicos da comunicação humana, funcionando como uma sentença completa ou um termo dentro da mesma, ocupando a posição de um substantivo, de um verbo, advérbio, adjetivo e outros componentes que marcam a situação conversacional (DOKE, 1935). As características apontadas por Bartens (2000) para definir os ideofones expressam ainda mais a íntima relação entre ideofones e o simbolismo sonoro de uma língua (LEE, 1992 e BARTENS, 2000). Todas as características apresentadas por Bartens (2000) foram levadas em consideração ao se proceder à análise dos dados.

Não se pretende aqui abranger todos os aspectos possíveis de seu enfoque, mas fazer uma descrição das características dos ideofones no PB. Espera-se, também, contribuir para estudos posteriores, visto que há ainda muito que se descobrir sobre a relação ideofones e simbolismo sonoro.

\section{PROBLEMATIZAÇÃO}

Com o objetivo de identificar herança do substrato africano no português brasileiro, Cruz (2000a), em seu estudo sobre o português 
falado por comunidades quilombolas do Pará (doravante ABP), aponta como marca de identidade lingüística das referidas comunidades os ideofones. Os ideofones estudados por Cruz (2000a) como típico do ABP são os presentes na tabela 1

Tabela 1- Exemplos de ideofones do ABP (cf. CRUZ, 2000a)

\begin{tabular}{|c|c|}
\hline Ideofone & Exemplo \\
\hline 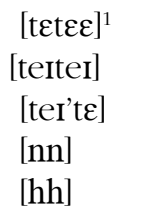 & $\begin{array}{l}\text { - eu pensava que ia morrer, falava coisa teteé. } \\
\text { - Ele está teitei de açaí. } \\
\text { - Vê se eles gostem que a gente tire o deles. Ela ainda ri teité. } \\
\text { - começa a se espalhar né? - hum, hum. } \\
\text { - em compromisso? - hem, hem". }\end{array}$ \\
\hline
\end{tabular}

Baseando-se em estudos que apresentam os ideofones como típicos das línguas africanas - (BARTENS, 1997; CHILD, 1994; WESCOTT, 1977; SAMARIN, 1965; NEWMAN, 1968) - os ideofones foram vistos pela autora, em um primeiro momento, como herança direta das línguas africanas pelo seu nítido processo de reduplicação (CRUZ, 2000b).

Entretanto, os ideofones não são apenas típicos das línguas africanas, eles fazem parte de línguas como coreano (CRUZ, 2000b; LEE, 1992), línguas indo-pacíficas munda (KUIPER, 1965), línguas indianas (EMENEAU, 1969), japonês (ALFONSO, 1966 e TAKEMOTO, 1998), algumas línguas indo-arianas (DIMOCK, 1957) e chinês. Constituem também a prova de influência direta do chinês no inglês falado em Singapura (LIM, 1998). Os mesmos ideofones identificados como típicos do ABP por Cruz (2000a) apresentam similaridades acentuadas de forma, função e significação com ocorrências encontradas em línguas indígenas da família tupi.

Assim como se atesta que os mesmos ideofones estudados por Cruz (2000a) pertencem ao sistema lexical e gramatical de línguas indígenas que sofreram forte influência da língua geral como tembé (BORGES, 1991), ou da própria língua geral amazônica (ARAÚJO, 1989), atesta-se também que eles pertencem a outras línguas que não fazem parte da família tupi-guarani como o guató (PALÁCIO, 1984), em que é possível encontrar a partícula afirmativa do ABP [NN]. Da mesma 


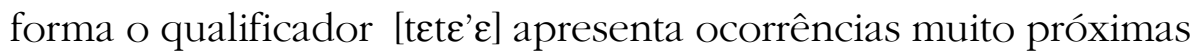
no Tembé (EIRÓ, 2001). Ver tabela 2.

Tabela 2 - Exemplos de ideofones em línguas indígenas

\begin{tabular}{|c|c|c|c|c|}
\hline Ocorrências & Transcrição & Função & Línguas & Fontes \\
\hline Hemhem & [hh] & $\begin{array}{l}\text { Partícula } \\
\text { afirmativa }\end{array}$ & Kamauirá & (SEKI, 2000) \\
\hline Humhum & [yy] & $\begin{array}{l}\text { Partícula } \\
\text { afirmativa }\end{array}$ & Guató & (PALÁCIO, 1984) \\
\hline $\begin{array}{l}\text { Teéteé, } \\
\text { Teteé, } \\
\text { Teuté }\end{array}$ & 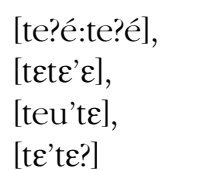 & Intensificador & $\begin{array}{l}\text { LGA,Ka'apor, } \\
\text { Makurapi } \\
\text { e Tembé }\end{array}$ & $\begin{array}{l}\text { (CALDAS, 2001; } \\
\text { BRAGA, 1992; } \\
\text { BORGES, 1991 } \\
\text { EIRÓ, 2001) }\end{array}$ \\
\hline
\end{tabular}

Do trabalho de Cruz (2000a), retiveram-se dois aspectos para revisão e aprofundamento:

1. A preferência do PB pelo traço bilabial na formação de seus ideofones;

2. os ideofones enquanto marca dialetal do ABP.

Resolvemos, portanto, aprofundar e avançar um pouco mais na descrição feita por Cruz (idem), buscando, desta vez, verificar as seguintes hipóteses:

a) O português brasileiro tem preferência pelo traço bilabial?

b) Em qual função gramatical há maior ocorrência de ideofones?

c) Qual tipo de significado é preferencialmente expresso pelos ideofones?

d) Os ideofones funcionam como marca dialetal?

e) Os ideofones funcionam como identidade lingüística do ABP?

f) Há alguma relação direta entre ideofones e língua tonal?

g) Os ideofones típicos do ABP seriam herança da língua geral amazônica?

h) Os ideofones seriam típicos de situações de fala informal, como conversas informais e narrativas orais? 


\section{METODOLOGIA}

Para comprovação das hipóteses acima listadas, procedeu-se da seguinte forma.

Primeiramente, recorreu-se a um levantamento dos dados nos corpora consultados, ou seja: em Bartens (2000), em Cruz (2000a), em Cassique (1995) e em Oliveira (2000).

Ampliou-se o corpus buscando verificar a ocorrência de ideofones na fala cotidiana, em particular em conversa informal, por anotação direta e sem utilização de gravador cassete. Coletaram-se, também, dados de revistas em quadrinhos infantis, com o objetivo de verificar se a produção de ideofones é típica de uma situação de fala em particular.

O universo pesquisado foi completado consultando-se trabalhos referentes a línguas indígenas brasileiras, dando preferência a estudos de descrição de línguas pertencentes à família tupi, uma vez que tudo indicava serem os ideofones típicos do ABP uma marca de influência da língua geral amazônica. Neste sentido, buscou-se um levantamento de dados em Araújo (1989), Braga (1992), Caldas (2001), Eiró (2001), Julião (1983), Maciel (1991), Rodrigues (1995) e Silva (1999).

Após o levantamento dos dados, passou-se para a etapa de sistematização dos dados e, para esta fase, utilizou-se o programa Excel. Uma planilha Excel possibilitou uma melhor visualização e uma melhor organização dos dados. Na planilha, os dados foram organizados, constando das seguintes informações: transcrição fonética, função gramatical, significação, variedade lingüística, situação de fala, fonte consultada, contexto e traço fonético dominante. Encontra-se, em anexo, um quadro (quadro 1) com os dados dos ideofones originais de Cruz (2000a, b). Uma vez tendo os dados sido organizados na planilha Excel, foi possível passar à análise quantitativa e qualitativa. Foi feita, primeiramente, uma triagem que tinha como objetivo observar a freqüência de ocorrências das características acima mencionadas por dado. Todos os resultados obtidos na análise foram organizados em gráficos para melhor visualização dos dados. 


\section{CORPUS FINAL}

Ao todo, identificaram-se 85 ideofones cuja distribuição por variedade lingüística do português brasileiro é a seguinte: (i) ABP (19 dados), (ii) AM-português da Amazônia (21 dados) e (iii) PBportuguês brasileiro padrão ( 45 dados).

Obtiveram-se também como material de comparação dados das principais línguas indígenas: Amanajá, Anambé, Kamaiurá, Ka'apor, Makurap, Makú, Parakanã, Tembé, Guató. Dessas línguas, obtiveram-se 29 ocorrências que chamaram atenção por sua forte semelhança de estruturação com os ideofones estudados, o que possibilitou continuar acreditando que os ideofones possuem uma forte influência das línguas indígenas no PB.

Portanto, 114 ocorrências de ideofones foram analisadas neste trabalho.

\section{ANÁLISE}

A organização dos dados nas planilhas permitiu um melhor tratamento dos dados coletados. O fator de maior controle efetivado foi a freqüência de ocorrência dos ideofones no corpus a partir de cada aspecto determinado como caracterizador dos ideofones (v. final do item 2). Obtiveram-se os seguintes resultados.

\subsection{Função gramatical}

Como já mencionado anteriormente, os dados coletados foram analisados sob vários aspectos; um desses aspectos está ligado à função gramatical dos ideofones. Esse aspecto foi cogitado em decorrência de uma das definições dos ideofones afirmar que estes são combinações sonoras que podem assumir funções na frase, recaindo sobre si, por exemplo, o papel de um verbo, de um designativo ou de um qualificador e assim por diante (BARTENS, 2000; DOKE, 1935). A seguir, alguns exemplos das diferentes funções morfossintáticas que podem ser assumidas por um ideofone. 


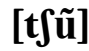

Apresenta função equivalente a de um verbo por expressar o ato de pular ou jogar-se.

(126) "... esses dois parceiros se jogaram na água aí ele $\mathbf{t c h u m}$ atrás."

(127) “...pulou n’água ele, doido $\boldsymbol{t c h u m ~ a t r a ́ s . " ~}$

\section{[teitei]}

Aparece freqüentemente nos dados com função de intensificador, tem o significado de 'cheio', 'muito' ou 'bastante'.

(138) "- Ele está teitei de açaí ."

\section{$[\eta \underline{y}]^{1}$}

O ideofone ‘bumbum'trata-se de uma partícula afirmativa.

(51) Locutor 1: "- é uma desculpa pra preguiça dele né tia?" Locutor 2: "- bumbum."

\section{$[\mathrm{hh}]^{2}$}

O ideofone 'hemhem' constitui uma outra partícula afirmativa.

(45) Locutor 1: "- foi por causa do marido?" Locutor 2: "- bembem."

\section{[tei't $\varepsilon$ ]}

O ideofone 'teité'é um qualificador, cujo significado é 'coitado' ou 'infeliz'.

(118) "- Vê se eles gostem que a gente tire o deles. Ela ainda ri teité."

Em decorrência desses papéis assumidos pelos ideofones, resolveu-se pesquisar que função gramatical é melhor e é mais representada na frase pelos ideofones do PB. O gráfico 1 ilustra os resultados alcançados. 


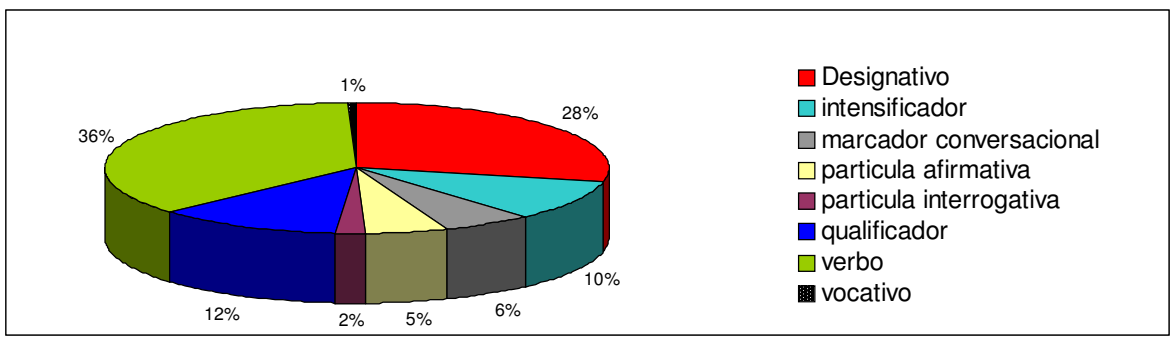

Gráfico 1 - Distribuição dos ideofones em funções gramaticais (total de 85 dados)

O gráfico 1 mostra que as funções gramaticais mais expressivas foram as de designação, intensificação, marcador conversacional, partículas afirmativas, partículas interrogativas, qualificadores e de verbos. Porém, de todas essas funções, o papel de verbo é o melhor representado pelos ideofones tanto no aspecto qualitativo como no quantitativo, chegando ao percentual de 36\% das ocorrências. Tal resultado é ratificado pelo gráfico 1 que mostra os ideofones como melhores representantes do campo semântico de ações, e, principalmente, ações ligadas à emissão de sons, como é possível ver mais adiante. Em segundo lugar, aparece a função de designativo com um bom percentual (28\%). As outras funções que aparecem com percentual significativo e que também estavam sendo esperadas são as funções de qualificadores (12\%) e intensificadores (10\%).

O próximo aspecto a ser observado diz respeito ao aspecto sociolingüístico. Procurou-se verificar qual variedade do português faz mais uso de ideofones como recurso lingüístico.

\subsection{Variedade lingüística}

A observação da distribuição dos ideofones nas variedades lingüísticas do português e em outras línguas brasileiras é importante para detectar se o uso de ideofones se dá em determinada variedade do português ou se é um traço lingüístico universal. O gráfico 2 reflete os resultados obtidos. 


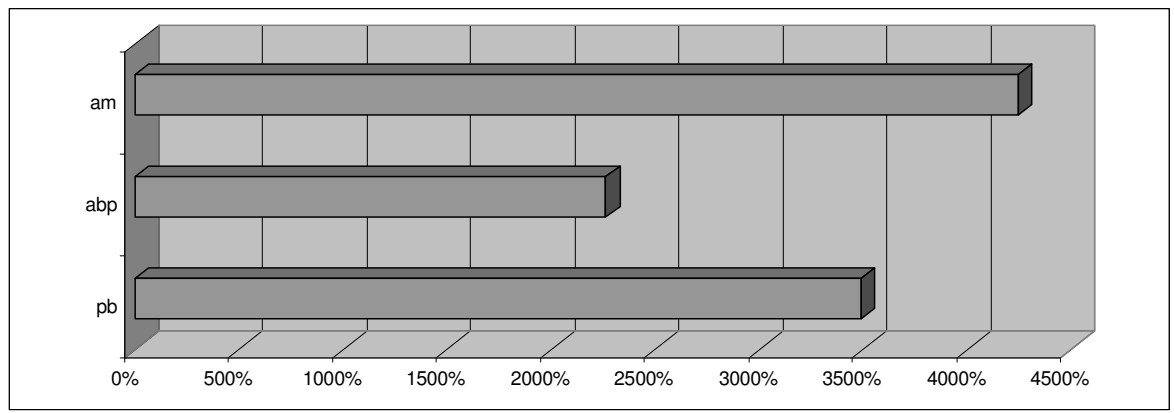

Gráfico 2 - Distribuição dos ideofones por variedade lingüística do português (total de 85 dados)

Os resultados da distribuição de ideofones nas variedades lingüísticas são claros em informar que, segundo a freqüência de ocorrências, o português regional da Amazônia (AM), com cerca de $42 \%$ das ocorrências, apresenta um maior uso de ideofones na sua comunicação. Observa-se também que no português brasileiro padrão (PB) se faz bastante uso de ideofones como recurso de expressividade simbólica 34\%. Esta primeira distribuição não apresenta os ideofones como uma marca dialetal de nenhuma variedade do português em particular. Abaixo, eis alguns exemplos de ideofones do português por variedade lingüística.

Variedade Lingüística

$\boldsymbol{A m}$

$A B P$

PB
Contexto

- agora malamá a vespera.

- Maparáfifiti.

- Eles estão tendo um teretetêe.
Fonte

(CAMPOS, 1998)

(CRUZ, 2000a)

Observação direta

\subsection{Traço bilabial geral}

Cruz (2000a) detectou que, no PB, existe uma preferência pelo uso de traço bilabial na formação de seus ideofones. Os exemplos a seguir ilustram a preferência por esse traço. 
Contexto

(09) -...ele só deu um pulo, bam e bacu no defunto.

(13) -...eu não sei o quê e bebebê, e bababá.

(76) - taquei-lhe na cara dele, pá e eu bacu.
Transcrição

[bã], [baku]

[bebe'be], [baba'ba]

[pa], [baku]

(33) - a minha teve nove filhos, um morreu gito logo que nasceu. [3itu]

(116) - Ele virou agora um teba de homem.

O gráfico 3 mostra essa disposição no português

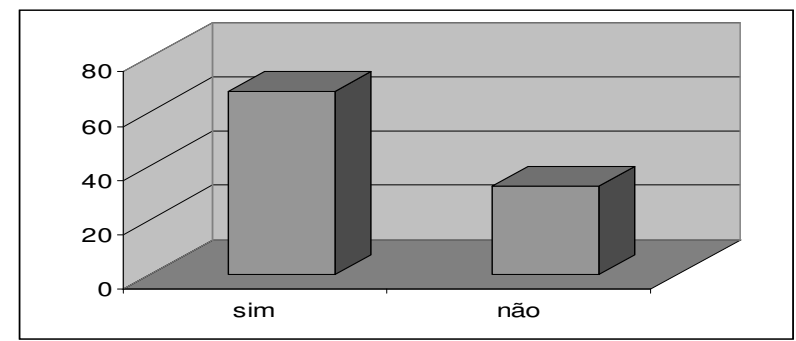

Gráfico 3 - Freqüência da ocorrência da articulação bilabial no conjunto dos dados (total de 114 dados)

Os dados obtidos e analisados confirmam a hipótese de Cruz (2000a) de que existe uma preferência maior pelo traço bilabial na formação da expressividade sonora do PB.

Para conhecer melhor essa preferência pelo traço bilabial na formação dos ideofones no português brasileiro, buscou-se saber se esta preferência permanece em todas as variedades lingüísticas ou se existe alguma que foge a essa regra. Observe o gráfico 4.

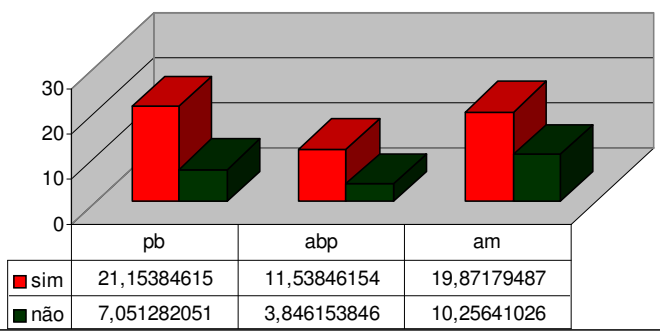

Gráfico 4 - Ocorrência de articulação bilabial nos ideofones por variação lingüística (total de 156 dados) 
Os dados confirmam a presença do traço bilabial como preferência no português brasileiro, principalmente pelo $\mathrm{PB}$, que apresentou um percentual bastante significativo de uso (21\%). Em segundo lugar tem-se o AM (19\%).

No caso do ABP, Cruz (2000a) já havia detectado que não existe essa preferência por traço bilabial nessa variedade do português em particular.

Percebe-se uma aproximação visível entre as línguas indígenas e o português brasileiro nos resultados a respeito da utilização de traço bilabial na formação dos ideofones. Ver o gráfico 5 .

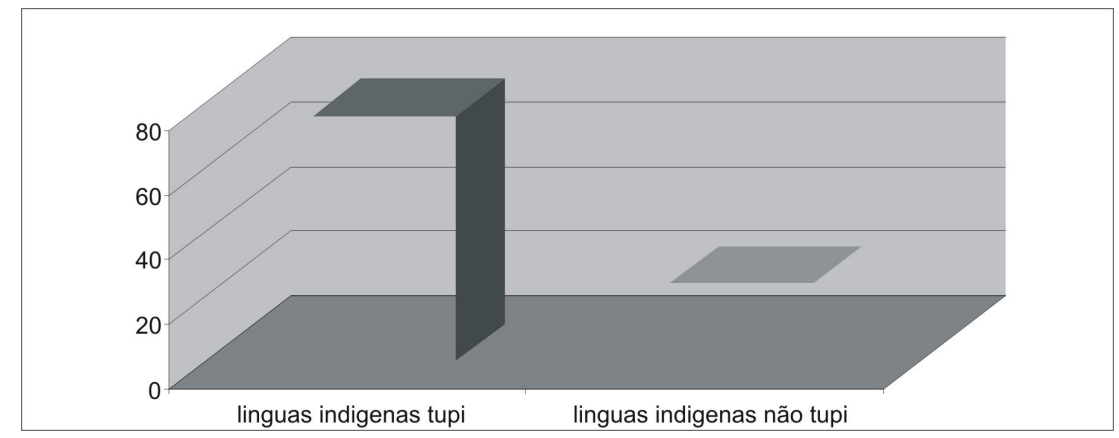

Gráfico 5 - Freqüência de articulação bilabial nas línguas indígenas

Os resultados mostram que as línguas indígenas de origem tupi também têm essa preferência pelo traço bilabial na formação de seus ideofones.

\subsection{Situação de fala}

A ocorrência em diferentes situações de fala foi outro aspecto importante a ser observado, pois assim fica claro se os ideofones do $\mathrm{PB}$, assim como os de outras línguas, apresentam preferência por uma determinada situação de fala. Fazendo a distribuição dos dados, alcançaram-se os seguintes resultados como mostra o gráfico 6. 


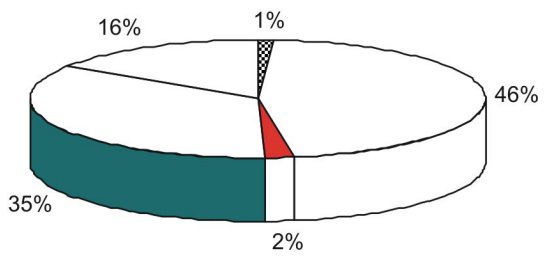

Anúncio publicitário

conversa informal língua escrita

m entrevista narrativas orais

Gráfico 6 - Distribuição dos ideofones em situação de fala

Os estudos anteriores delinearam características dos ideofones em várias línguas como o coreano (LEE, 1992), japonês (TAKEMOTO, 1998), crioulos do atlântico (BARTENS, 1997), africano (CHILD, 1994) e inglês (WESCOTT, 1977). Entre as já citadas está evidente a preferência de utilização de ideofones na comunicação oral. No gráfico 6 percebe-se que os ideofones do PB apresentam essa mesma característica, pois o fenômeno foi pouco encontrado em língua escrita que tem apenas $2 \%$ dos dados nesta modalidade. Tal resultado explica o motivo pelo qual a observação dos dados em revistas em quadrinhos não aparece no trabalho, pois não foram detectadas ocorrências suficientes para que participassem do corpus utilizado. A maior ocorrência de ideofones se deu na situação de conversa informal com $46 \%$ das ocorrências. As entrevistas e as narrativas orais aparecem com 35\% e 16\% das ocorrências, respectivamente.

\subsection{Campo semântico}

Ao proceder-se a um levantamento do campo semântico melhor representado pelos ideofones, alcançou-se um nível bastante significativo de compreensão dos mesmos, e até uma melhor descrição (ver o gráfico 7). A seguir são mostrados alguns dos campos semânticos abrangidos pelos ideofones. 


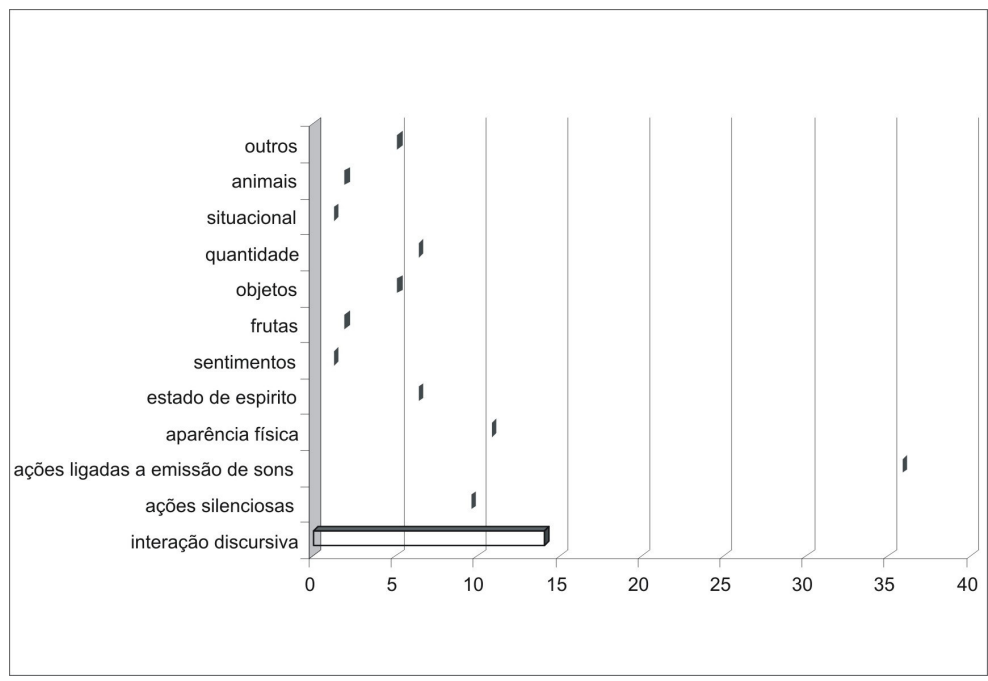

Gráfico 7 - Preferência do campo semântico dos ideofones

\section{[dridridri]}

Esse é um ideofone que está relacionado semanticamente com ações ligadas a emissão de sons

(31) "...ele com o defunto na...no ombro e dridridri e ele atrás."

\section{[pa]}

O ideofone $\boldsymbol{p a}$, nesta frase, está ligado semanticamente a interações discursivas.

(77) “...pá conversa vai pá conversa vem.”

\section{[zito]}

O ideofone 'jito' está relacionado à idéia de intensificação, de pequeno.

(40) "Eu vi um passarinho jito, jito."

\section{[teb]}

O ideofone 'teba' também está relacionado à idéia de intensificação, mas como aumentativo.

(129) "Ele virou agora um teba de homem." 
O gráfico 7 demonstra que, preferencialmente, os ideofones optam por representações de ações; tal fato anda em harmonia com os resultados obtidos no gráfico 7. Porém, uma observação importante é que essas ações preferenciais estão ligadas à emissão de um som. Esta observação nos faz relacionar o som emitido por uma ação à estrutura e ao significado expresso pelo ideofone.

Nos dados coletados para o presente trabalho, é possível perceber também que existe uma semelhança entre os sons utilizados na estruturação desses dados e os sons tradicionalmente ligados à idéia de bater, cair, pular, etc. (ver tabela 3). E tal fato mostra que os sons produzidos por essas ações estão representados na estruturação dos ideofones majoritariamente estudados. A relação direta entre a idéia do som produzido pela ação e os sons utilizados para sua representação nos ideofones expressa uma relação icônica e, logo, simbólica. Sendo o simbolismo intimamente ligado à significação, eis a razão de uma relação entre ideofones e simbolismo sonoro.

Tabela 3 - Ideofones representando ações ligadas à emissão de som

\begin{tabular}{|c|c|c|}
\hline Ideofone & Exemplo & Significação \\
\hline [pa] & - taquei- lhe na cara dele, pá e eu bacu. & Bater \\
\hline ['baku] & - taquei- lhe na cara dele, pá e eu bacu. & Bater \\
\hline [tfãw] & - arrastou na cabeça da velha pá, tchão. & Cair \\
\hline$\left[\mathrm{t} \int \tilde{\mathrm{u}}\right]$ & - ...pulou n’agua ele, tchum atrás & Pular \\
\hline
\end{tabular}

Outro resultado muito importante, e já esperado, diz respeito à interação discursiva preferida pela maioria dos ideofones também confirmado pelo gráfico 6, que mostra uma maior presença de ideofones na conversa informal.

\section{RESULTADOS}

Tomando como base a análise feita no item anterior, os dados mostram as seguintes respostas às perguntas do item 2: 
a) o português brasileiro tem preferência pelo traço bilabial na formação de seus ideofones. Os resultados confirmam a hipótese de Cruz (2000a) que já indicava como tendência do PB a utilização do traço bilabial na formação dos ideofones;

b) o verbo é a função gramatical mais representada por ideofones na oração;

c) conseqüentemente, há uma preferência de ideofones na representação do campo semântico de ações relacionadas à emissão de sons;

d) constatou-se que as ocorrências de ideofones se deram com um significativo percentual em quase todas as variedades, o que nos leva a concluir que não se trata de uma identidade lingüística do ABP, mas sim um processo que ocorre em diversas variedades do PB. A única característica peculiar dos ideofones do ABP continua sendo que os mesmos não têm preferência pelo traço bilabial;

No entanto, a presença ativa de ideofones em línguas tonais nos dá elementos para continuar investigando se a formação de ideofones em uma língua é uma característica universal ou típica de línguas tonais;

e) como foi encontrado um bom percentual de ideofones nas variedades lingüísticas estudadas, conclui-se que os ideofones não servem como marca dialetal de uma determinada variedade do PB;

f) os ideofones do português brasileiro encontram-se essencialmente na modalidade oral e se fazem mais presentes na fala espontânea.

\section{CONCLUSÃO}

O estudo dos ideofones do português brasileiro mostram que há: a) a preferência pelo traço bilabial na formação dos mesmos e b) a preferência pela representação de ações relacionadas à emissão de sons.

O fenômeno ocorreu proporcionalmente nas três diferentes variedades lingüísticas, o que leva a concluir que: a) os ideofones não constituem uma marca dialetal do ABP, pois detectou-se que a 
característica peculiar do mesmo é a não preferência pelo traço bilabial na formação de seus ideofones; b) igualmente aos demais ideofones estudados em outras línguas, os ideofones do português brasileiro se fazem presentes na comunicação oral e, principalmente, na fala espontânea como conversa informal, entrevistas e narrativas orais.

Como assinalado na introdução deste artigo, foi possível abordar apenas alguns processos estudados no PB. A certeza deixada aqui é a da necessidade de se conhecer melhor o funcionamento do PB no que diz respeito ao seu sistema simbólico e seus recursos lingüísticos na comunicação oral.

\section{NOTAS}

${ }^{1}$ Cruz (1994) apresenta uma descrição detalhada dessa partícula afirmativa na variedade lingüística do ABP.

${ }^{2}$ Idem.

${ }^{3}$ Para a transcrição dos dados foi utilizado o alfabeto SAMPA.

\section{REFERÊNCIAS BIBLIOGRÁFICAS}

ARAÚJO, L. S. de. Aspectos da língua Gavião- Jê: vocabulário. 1989. Tese (Doutorado) - Rio de Janeiro.

ALFONSO, A. Japanese language patterns. Tokyo: Sophia University Press, 1966. V. 1, p. 450- 454.

BARBOSA, J. F. Contribuição ao conbecimento da lingua Amanajé. Belém: UFPA, 2002.

BARTENS, A. Ideofones and sound simbolism in Atlantic creoles, Abstract for the SPCL, conference at the University of Westminster, London, June 1997, p. 26-28.

BARTENS, A. Ideophones and sound symbolism in Atlantic creoles. Helsinki: The Finnish Academyc of Sciences, 2000. 168p.

BORGES, L. C. A lingua geral amazônica: aspectos de sua fonêmica. 1991. 98 f. Dissertação (Mestrado) - IEL /Unicamp.

BRAGA, A. de O. A fonologia segmental e aspectos morfológicos da lingua Makurap (TUPI). 1992. Dissertação (Mestrado) - Unicamp, Campinas. 
CAMPOS, B.; OlIVEIRA, J. Do Pucuru à Panelinha: dados do vocabulário mocajubense. Cametá: UFPA, 1998.

CALDAS, R. B. C. Aspectos, modos de ação e modalidade na língua Ka'apor. 2001. Dissertação (Mestrado) - UFPA.

CASSIQUE, O. "Os Tambouros do Itapocú”: relatório científico do projeto Marcas Lingüísticas da fala das comunidades negras de Cametá, Belém, Pará, 1995.

CASTILHO, A. O português do Brasil. In: ILARI, R. (Ed.). Lingüística Românica, São Paulo: Ática, 1992. p. 237-269.

CHILD, G. African Ideophones. In: NICHOLS, L. J.; OHALA, J. (Ed.). Studies in Sound Symbolism. Cambridge: University Press, 1994. p.178-204.

CRUZ, R. Sound Symbolism in Brazilian Portuguese: a study of ideophones. In: The procedings of the conference gesture: meaning and use, Porto (Portugal): Universidade de Fernando Pessoa, 2000a.

CRUZ, R. Analyse phonologique et acoustique du portugais parlé par des communautés noires de l'Amazonie (Brésil). 2000b. Tese (Doutorado) - Université de Provence.

DIFFLOTH, G. Notes on Expressive Language. In: Proceedings of the Chicago Linguistic Society 8, 1972.

DOKE, C. M. Bantu Linguistics Terminology. London: Longmans, Green, 1935.

DIMOCK, E. C. Symbolic forms in Bengali. Bulletin of the Deccan College Research Institute, 1957, v. 18, p. 22-28.

EIRÓ, J. G. Contribuição à análise fonológica da língua Tembé. Belém: UFPA, 2001.

EMENEAU, M. B. Onomatopoetics in the Indian linguistics area. Language, v. 45, p. 274-299, 1969.

FORDYCE, J. F. Studies in Sound Symbolism with Special Referent to English. PhD dissertacion, University of California at Los Angeles, 1988.

JULIÃO, M. R. A língua dos índios do rio Cairari. Belém: UFPA, 1993.

KUIPER, F. B. J. Consonantes variation in Munda, Indo-Pacific Linguistic Studies, part 1, North- Holland, Amsterdan, 1965, p. 54-89.

LEE, J-S. Phonology and sound symbolism of Korean ideophones. 1992. $379 \mathrm{f}$. (Dissertacions) - UMI.

LIM, L. We talklike that Meh? No, Lah!: intonation patterns on pragmatic particles in spontaneous Singapore English- Preliminary observations. National University of Singapore, in Sound partterns of Spontaneous Speech: productiuon and perception. La Baume-Les-Aix, septembre, 1998. 
LEÃO, J.; GOMES, L. Um estudo semântico de palavras não dicionarizadas no linguajar cametaense: à busca de brasileirismo. Cametá: UFPA, 1998.

MARTIN, S. E. Phonetic Symbolism in Korean. Uralic and Altaic Series, v. 13, Indian, 1962, p177- 189.

MACIEL, I. Alguns aspectos fonológicos e morfológicos da língua Máku. 1991. Dissertação (Mestrado) - Brasília.

NEWMAN, P. Ideophones from a syntactic point of view. Journal of west African Languages, Cambridge University Press, London, v. 2, p. 107-117, 1968.

OLIVEIRA, M. Prosodic Features in Spontaneous Narrativas. 2000. $241 \mathrm{f}$. Dissertation ( PhD.) - Simon Frase University.

PALÁCIO, A. P. Guató- a língua dos índios canoeiros do rio Paraguai. 1984. Tese (Doutorado) - UNICAMP, Campinas.

RODRIGUES, C. L. R. Estude morphosyntaxique de la langue Xipaya. 1995. Tese (Doutorado) - Paris.

SAMARIN, W. J. Perspectives on African Ideophones, African Studies, xxiv, p. 117-121, 1965.

SEKI, L. Gramática do Kamaiurá: Lingua Tupi-guarani do Alto Xingu. Campinas, SP: Editora UNICAMP; São Paulo, SP: Imprensa Oficial, 2000.

SILVA, A. C. S. e. Aspectos da referência alternada em Parakanã. 1999. Dissertação (Mestrado) - UFPA, Belém.

TAKEMOTO, E. Vocalisation des gestes: les idéophones japonais. In: SANT, S. et al. (Ed.). Oralité et Gestatualité: communication multimodale, interaction, 1998, p. $539-542$.

TRINDADE, R. O som da fala dos pescadores de Cametá. 1992. Dissertação (Mestrado) - Departamento de Lingüistica - Universidade Federal de Santa Catarina. WESCOTT, R. Ideophones in Bini and English. Forum Linguisticum (2), 1977. 
Quadro 1 - Ideofones identicados por Cruz

\begin{tabular}{|c|c|c|c|c|c|c|c|}
\hline Ideofone & $\begin{array}{l}\text { Transcrição } \\
\text { Fonética }\end{array}$ & $\begin{array}{l}\text { Classe } \\
\text { gramatical }\end{array}$ & Significação & $\begin{array}{l}\text { Variação } \\
\text { lingüística }\end{array}$ & $\begin{array}{l}\text { Situação } \\
\text { de fala }\end{array}$ & Fonte & $\begin{array}{l}\text { Exemplo } \\
\text { de ocorrência }\end{array}$ \\
\hline Fifiti & [fi'fitfi] & Intensificador & Minúsculo & $\mathrm{ABP}$ & $\begin{array}{l}\text { Conversa } \\
\text { Informal }\end{array}$ & Cruz (2000b) & Mapará fifiti \\
\hline Gito & [zitu] & Intensificador & Diminutivo & $\mathrm{ABP}$ e $\mathrm{AM}$ & $\begin{array}{l}\text { Conversa } \\
\text { Informal }\end{array}$ & $\begin{array}{l}\text { Cruz (2000a, } \\
2000 \mathrm{~b})\end{array}$ & $\begin{array}{l}\text { Eu vi um passarinho } \\
\text { jito, jito }\end{array}$ \\
\hline Hem, hem & {$[\mathbf{h h}]$} & $\begin{array}{l}\text { Partícula } \\
\text { afirmativa }\end{array}$ & Sim & $\mathrm{ABP}$ & Entrevista & $\begin{array}{l}\text { Cruz (2000a, } \\
\text { 2000b, 1994) }\end{array}$ & $\begin{array}{l}\text { - em compromisso? } \\
\text { - hem, hem }\end{array}$ \\
\hline Hum, hum & [yg] & $\begin{array}{l}\text { Partícula } \\
\text { afirmativa }\end{array}$ & Sim & $\mathrm{ABP}$ & $\begin{array}{l}\text { Conversa } \\
\text { Informal }\end{array}$ & $\begin{array}{l}\text { Cruz (2000a, } \\
\text { 2000b, 1994) }\end{array}$ & $\begin{array}{l}\text { - começa a se espalhar } \\
\text { né? - hum,hum }\end{array}$ \\
\hline Malamá & [mala'ma] & $\begin{array}{l}\text { Intensificador, } \\
\text { qualificador }\end{array}$ & $\begin{array}{l}\text { não muito, } \\
\text { mais ou menos } \\
\text { quase }\end{array}$ & $\mathrm{ABP} / \mathrm{AM} / \mathrm{PB}$ & Entrevista & $\begin{array}{l}\text { Cruz }(2000 a, \\
2000 b, 1996)\end{array}$ & $\begin{array}{l}\text { - eu vou pedir pra tua tia } \\
\text { fazer um ché malamá doce. }\end{array}$ \\
\hline Teba & [teb] & Intensificador, & Aumentativo & $\mathrm{ABP} / \mathrm{AM}$ & $\begin{array}{l}\text { Conversa } \\
\text { Informal }\end{array}$ & $\begin{array}{l}\text { Cruz }(2000 b \text {, } \\
2000 \mathrm{a}, 1996)\end{array}$ & $\begin{array}{l}\text { - Ele virou agora um } \\
\text { teba de homem }\end{array}$ \\
\hline Teité & [tzĩ't te] & Qualificador & Coitado, infeliz & $\mathrm{ABP}$ & & $\begin{array}{l}\text { Cruz }(2000 a, \\
2000 b, 1996)\end{array}$ & $\begin{array}{l}\text { - era para apruntare } \\
\text { essa capelinha aí, } \\
\text { mas pobre teité num } \\
\text { faz o que quer. }\end{array}$ \\
\hline Teitei & [ter'teI] & Intensificador & $\begin{array}{l}\text { Muito, bastante, } \\
\text { cheio }\end{array}$ & $\mathrm{ABP}$ & $\begin{array}{l}\text { Conversa } \\
\text { Informal }\end{array}$ & $\begin{array}{l}\text { Cruz }(2000 a \\
2000 b, 1996)\end{array}$ & - Ele está teitei de açaí \\
\hline Teteé & [tete' $\varepsilon]$ & Intensificador & à toa & $\mathrm{ABP}$ & Entrevista & $\begin{array}{l}\text { Cruz (2000a, } \\
\text { 2000b, 1996) }\end{array}$ & $\begin{array}{l}\text { - eu pensava que ia morrer, } \\
\text { falava coisa teteé }\end{array}$ \\
\hline
\end{tabular}

